\title{
Simultaneous Multiplexed Detection of Protein and Metal Ions by a Colorimetric Microfluidic Paper-based Analytical Device
}

\author{
Xiaolu Xiong ${ }^{1,2}$, Junlin Zhang ${ }^{1}$, Zhou Wang ${ }^{1}$, Chenchen Liu ${ }^{1}$, \\ Wende Xiao ${ }^{1,2}$, Junfeng Han iD $^{1,2, *}$ \& Qingfan Shi $\left(D^{1, *}\right.$
}

Received: 16 May, 2020 / Accepted: 14 September, 2020 / Published online: 27 October, 2020

(C) The Korean BioChip Society and Springer 2020

\begin{abstract}
In order to improve the efficiency of disease diagnosis and environmental monitoring, it is desirable to detect the concentration of proteins and metal ions simultaneously, since the current popular diagnostic platform can only detect proteins or metal ions independently. In this work, we developed a colorimetric microfluidic paper-based analytical device $(\mu \mathrm{PAD})$ for simultaneous determination of protein (bovine serum albumin, BSA) and metal ions [Fe(III) and $\mathrm{Ni}(\mathrm{II})]$. The $\mu \mathrm{PAD}$ consisted of one central zone, ten reaction zones and ten detection zones in one device, in which reaction solutions were effectively optimized for different types of chromogenic reactions. Fe(III), Ni(II) and BSA can be easily identified by the colored products, and their concentrations are in good accordance with color depth based on the established standard curves. The detection limits are $0.1 \mathrm{mM}$ for Fe(III), $0.5 \mathrm{mM}$ for $\mathrm{Ni}(\mathrm{II})$ and $1 \mu \mathrm{M}$ for BSA, respectively. Best of all, we demonstrated the efficiency of the $\mu$ PAD with accurate detection of $\mathrm{Fe}$ (III), Ni (II) and BSA from river water samples within 15 minutes. The $\mu \mathrm{PAD}$ detection is efficient, instrument-free, and easy-to-use, holding great potential for simultaneous detection of cross type analytes in numerous diagnostic fields.
\end{abstract}

${ }^{1}$ Key Laboratory of Advanced Optoelectronic Quantum Architecture and Measurement, Ministry of Education, School of Physics, Beijing Institute of Technology, Beijing, 100081, China

${ }^{2}$ Micronano Centre, Beijing Key Lab of Nanophotonics \& Ultrafine Optoelectronic Systems, Beijing Institute of Technology, Beijing, 100081, China

*Correspondence and requests for materials should be addressed to Junfeng Han (®pkuhjf@bit.edu.cn) and

Qingfan Shi ( $\square$ qfshi123@bit.edu.cn)
Keywords: Microfluidic paper-based analytical device, Colorimetric detection, Simultaneous, Fe(III), Ni(II), BSA

\section{Introduction}

Proteins and metal ions are vital in life processes ${ }^{1-2}$. However, excessive intake of these essential biomolecules can lead to various diseases. For example, excess proteins can hinder functions of liver and kidney, ${ }^{3}$ the accumulation of iron increases the risk of anemia in the human body ${ }^{4}$, and a high level of nickel causes a variety of cancers ${ }^{5}$. Therefore, efficient monitoring proteins and metal ions is urgently needed for human health. ${ }^{6}$ Many methods have been used to detect the proteins and metal ions in drinking water, food and biological fluids ${ }^{7-11}$. For instance, the enzyme-linked immunosorbent assay (ELISA) can determine proteins sensitively ${ }^{12}$, inductively coupled plasma atomic emission spectrometry (ICP-AES) detects multiple metal ions at very low detection limits $^{13-14}$, the liquid crystal-based chemical sensors is currently explored for detection of multiple metal ions effectively ${ }^{15}$ and the chromatography is able to determine multiple metal ions or proteins individual$1 y^{16-17}$. However, these techniques require not only expensive instruments but also fail to execute the simultaneous detection of cross type analytes at a time.

In the recent ten years, $\mu$ PADs (microfluidic paper-based analytical devices) coupled with colorimetric assay are particularly attractive due to the instrument-free and easy-to-use features ${ }^{18-20}$. The specific chromogenic reactions in $\mu \mathrm{PADs}$ provide high-con- 
trast color signal, so qualitative analysis is easy to realize by naked eyes ${ }^{21}$. Sensitive quantified measurements can be further accomplished through daily smartphone, iPad or digital camera, combined with the supporting software ${ }^{22}$. For instance, Jayawardane et al. performed 15 replicate colorimetric measurements of reactive phosphate on a single $\mu \mathrm{PAD}^{23}$. Fang $\mathrm{Li}$ et al. reported a $\mu \mathrm{PAD}$ for multiplexed colorimetric determination of six metal ions together ${ }^{24}$. $\mathrm{S}$. Teepoo et al. reported a $\mu \mathrm{PAD}$ for simultaneous colorimetric detection of sucrose, fructose and glu$\operatorname{cose}^{25}$. Unfortunately, these previous colorimetric detections were still limited to a single type of molecules such as macro molecules or micro molecules in one device. In fact, the simultaneous determination of two different types of chemical contaminants was realized in food by using $\mu$ PADs technology, but it must be combined with fluorescence and rely on special complex instruments and trained personnel ${ }^{26}$.

In this work, a simple, rapid and effective colorimetric method is developed for the simultaneous detection of $\mathrm{Fe}(\mathrm{III}), \mathrm{Ni}(\mathrm{II})$ and BSA, as shown in Scheme 1. The assay combines a $\mu$ PAD with different types of chromogenic reactions in a device. Four patterns were first designed to array in one mask, and then both the photoresist type and the spin coating speed were optimized for the proper volume of flow passage in a $\mu \mathrm{PAD}$. What's more, the injection interval time of reaction solution was optimized for simultaneous detection. According to the color palette, each color represent corresponding target, while the varying color depth corresponds to changing concentration. The calibration curves were further generated by drawing the color intensity as a function of concentration. Best of all, the convenience and efficiency of our device were verified by applying it to the detection of $\mathrm{Fe}(\mathrm{III}), \mathrm{Ni}(\mathrm{II})$ and BSA in natural river samples.

\section{Results and Discussion}

\section{Effective Control of the Flow Passage Volume}

Suitable volume of flow passage is necessary for simultaneous detection of macro and micro molecules. The volume of flow passage is well-controlled by optimizing the thickness of photoresist in two steps. Firstly, photoresist types should be selected carefully. The photoresist SU-8 3050 was too sticky to spread uniformly on paper and the photoresist SU8 1050 was too thin to provide enough volume of flow passage, so SU8 GM-1075 was selected and verified in the subsequent experiment. Secondly, photoresist should be spun at a suitable speed. $1700 \mathrm{rpm}$ was selected for spin coating and the thickness of photoresist obtained was $100 \pm 10 \mu \mathrm{m}$ (Figure 1), while in Whites' method the filter paper was soaked in the photoresist
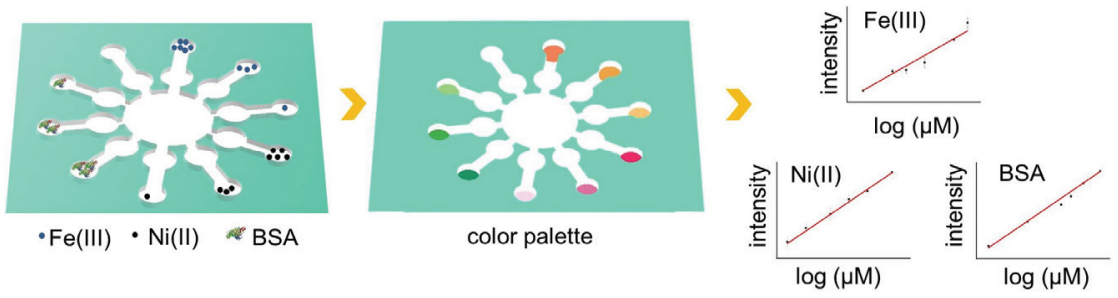

Scheme 1. Schematic of the $\mu \mathrm{PAD}$ for simultaneous multiplexed detection of Fe(III), Ni(II) and BSA.

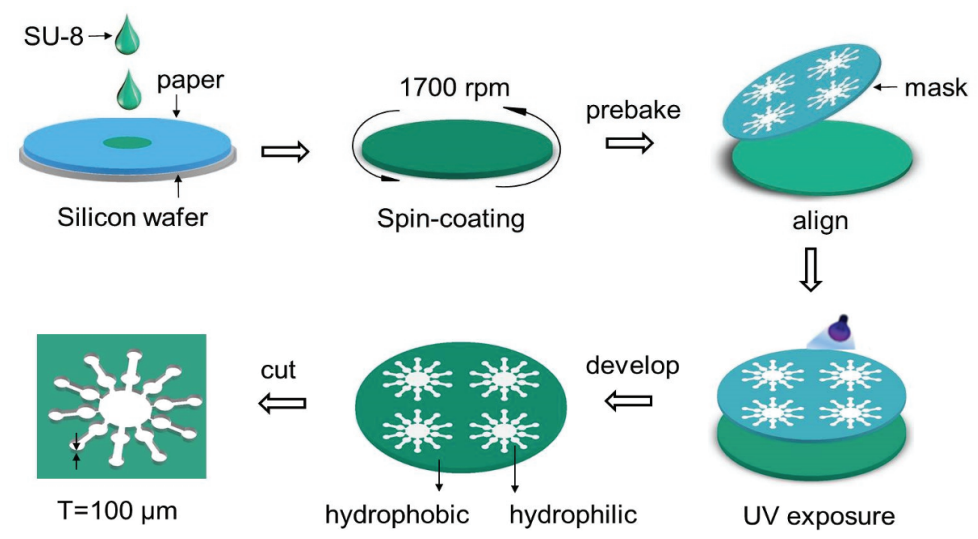

Figure 1. Main steps of fabricating $\mu$ PADs by UV-exposure method. 


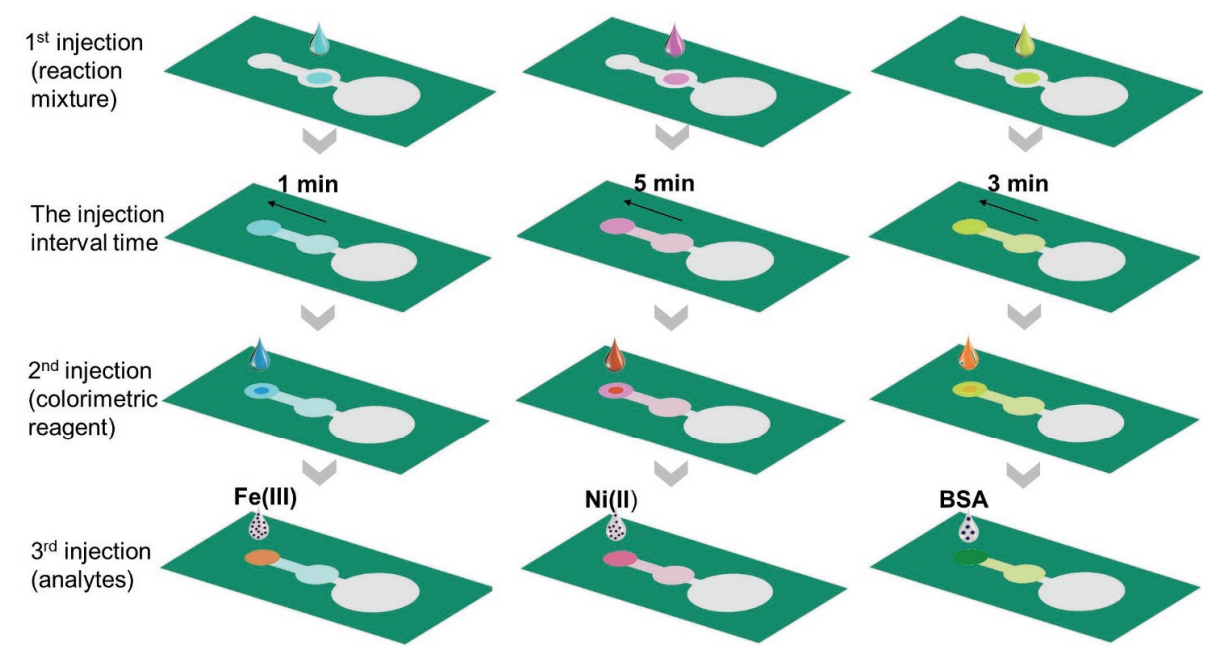

Figure 2. The injection process and interval time of reaction mixture and colorimetric reagent for detection of $\mathrm{Fe}(\mathrm{III})$, Ni(II) and BSA.

and the thickness of photoresist was not controlled ${ }^{27-28}$. Compared with other fabrication methods such as wax printing and inkjet printing ${ }^{29-32}$, UV exposure method has the advantage of effectively controlling the flow passage volume by selecting the appropriate SU-8 photoresist type and spin coating speed.

\section{Optimization of the Injection Interval Time of Reaction Solution}

To achieve the best performance of the $\mu \mathrm{PAD}$ for simultaneous detection of $\mathrm{Fe}(\mathrm{III}), \mathrm{Ni}(\mathrm{II})$ and BSA, the injection interval time for each detection was optimized as shown in Figure 2. For the detection of $\mathrm{Fe}(\mathrm{III})$, after reaction mixture solution 1 diffused and infiltrated naturally into the detection zone for $1 \mathrm{~min}$, phenanthroline can drop into the detection zone, so that the chromogenic reaction can be fully carried out. For the detection of $\mathrm{Ni}(\mathrm{II})$, the optimum injection interval time between the reaction mixture solution 2 and DMG solution was $5 \mathrm{~min}$, which was the appropriate time for diffusion and permeation into the detection zone. The long time led to evaporation of the solution, while the short time made the solution difficult to penetrate completely. For the detection of BSA, the injection interval time of 3 mins was a key factor for the diffusion and immersion of reaction mixture solution 3 into the detection zone, and then tetrabromophenyl blue was introduced to the detection zone.

\section{Colorimetric Palettes for Simultaneous Detection of $\mathrm{Fe}(\mathrm{III}), \mathrm{Ni}$ (II) and BSA}

For the detection of Fe(III), 1,10-phenanthroline was used as the colorimetric reagent that reacted with $\mathrm{Fe}$ (II) forming an orange complex. Hydroxylammonium chloride was first served as the reductant to reduce $\mathrm{Fe}(\mathrm{III})$ to $\mathrm{Fe}(\mathrm{II})$ and also as the masking agent to complex possible interfering metals $\mathrm{Ni}, \mathrm{Zn} \mathrm{Cd}$ and $\mathrm{Co}^{33}$. Ammonium acetate provided the acid environment for the chromogenic reaction. For the detection of $\mathrm{Ni}(\mathrm{II})$, dimethylglyoxime was used as the colorimetric reagent that reacted with $\mathrm{Ni}(\mathrm{II})$ producing a pink complex. Sodium fluoride and acetic acid masked the interference from $\mathrm{Fe}(\mathrm{III})$ and $\mathrm{Co}(\mathrm{II})$, and ammonium hydroxide solution provided $\mathrm{pH} 9.0$ environment for chromogenic reaction ${ }^{34}$. For the detection of BSA, tetrabromophenyl blue was used as the chromogenic reagent that reacted with BSA forming a green complex ${ }^{27}$. Sodium citrate buffer and hydrochloric acid solution provided $\mathrm{pH}$ 1.8-2.0 environment for chromogenic reaction.

The simultaneous detection result is displayed in Figure 3. For the first device (Figure 3a), detection zones 1-3 exhibited weak, light and bright orange, corresponding to $0.1,0.7$ and $5 \mathrm{mM} \mathrm{Fe}(\mathrm{III})$. Detection zones 4-6 showed weak, light and dark pink, corresponding to $0.5,5$ and $50 \mathrm{mM} \mathrm{Ni}(\mathrm{II})$. Detection zones 7-9 displayed dots of green, shallow and deep green, corresponding to $0.001,0.03$ and $0.1 \mathrm{mM}$ BSA. The detection area 10 displayed yellow as the control zone.

Based on the result of the first device, the second and third devices were used to explore the concentration in a wider and finer range. The color palette in the second device is displayed in Figure 3b. Detection zones 1-3 exhibited light to dark orange, corresponding to 0.3 to $10 \mathrm{mM} \mathrm{Fe}(\mathrm{III})$. Detection zones 


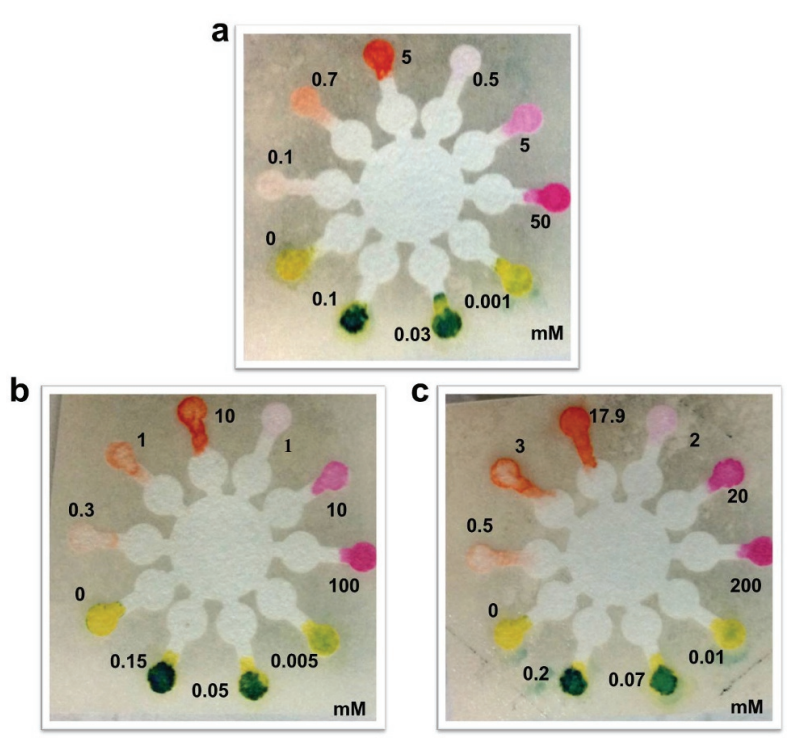

Figure 3. Color palettes for visual simultaneous determination of $\mathrm{Fe}(\mathrm{III}), \mathrm{Ni}(\mathrm{II})$ and BSA. (a) Chromogenic reactions for 0.1 , 0.7 and $5 \mathrm{mM} F e($ III), $0.5,5$ and $50 \mathrm{mM} \mathrm{Ni(II),0.001,0.03}$ and 0.1mM BSA. (b) Chromogenic reactions for 0.3, 1 and 10

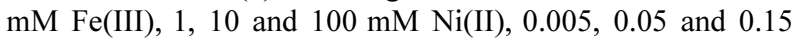
mM BSA. (c) Chromogenic reactions for $0.5,3$ and $17.9 \mathrm{mM}$ Fe(III), 2, 20 and $200 \mathrm{mM} \mathrm{Ni(II),} \mathrm{0.01,} 0.07$ and $0.2 \mathrm{mM}$ BSA. Yellow corresponds to $0 \mathrm{mM}$ BSA as control.

4-6 showed light pink to rose red, corresponding to 1 to $100 \mathrm{mM} \mathrm{Ni(II).} \mathrm{Detection} \mathrm{zones} \mathrm{7-9} \mathrm{displayed}$ shallow to dark green, and the color deepened with the increase of the concentration of BSA from 0.005 to $0.15 \mathrm{mM}$. The detection result of the third chip is shown in Figure 3c. In accordance with the color change trend of the front two devices, the color in the third device was still deepened as the concentration increased. Thus color palettes provide a quick and rough qualitative analysis, and the following calibration curves are required for the further quantitative systematic analysis.

\section{Generation of Calibration Curves for Fe(III), Ni(II) and BSA}

Calibration curves for $\mathrm{Fe}(\mathrm{III}), \mathrm{Ni}(\mathrm{II})$ and BSA are shown in Figure 4. The unit of $\mu \mathrm{M}$ was chosen to make sure the value on abscissa axis being positive. It can be found that the relationship between color intensity and logarithmic concentration behaved good linear in wide dynamic ranges. For the detection of $\mathrm{Fe}(\mathrm{III})$, the linear range was $0.1-5 \mathrm{mM}$ and detection limit was $0.1 \mathrm{mM}$, respectively. For the detection of $\mathrm{Ni}(\mathrm{II})$, the linear range and detection limit were 1-50 $\mathrm{mM}$ and $0.5 \mathrm{mM}$, respectively. For the detection of BSA, the linear range was $1-100 \mu \mathrm{M}$ and detection limit was $1 \mu \mathrm{M}$. The detection range of our $\mu \mathrm{PAD}$ is very wide, which make it great potential in the water pollution detection.
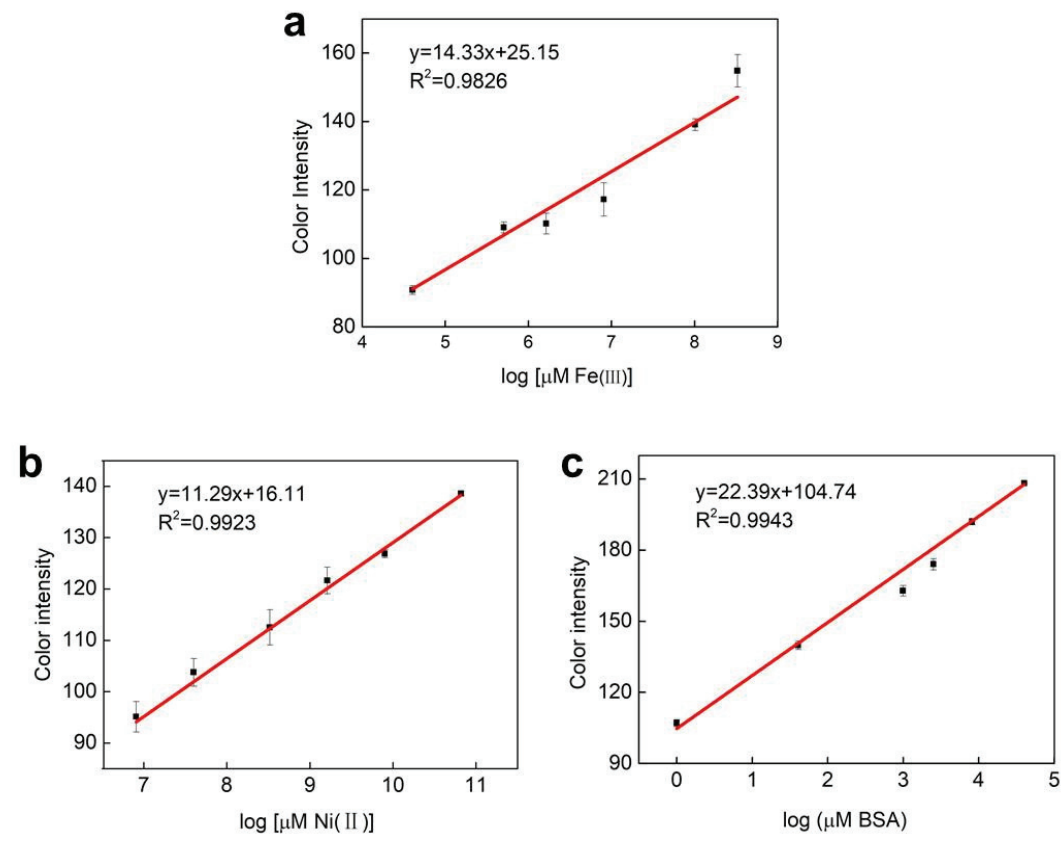

Figure 4. Calibration curves between color intensity and log target concentration for (a) Fe(III), (b) Ni(II), and (c) BSA detection. The error bars present standard deviation (SD) obtained from three independent measurement $(\mathrm{n}=3)$. 


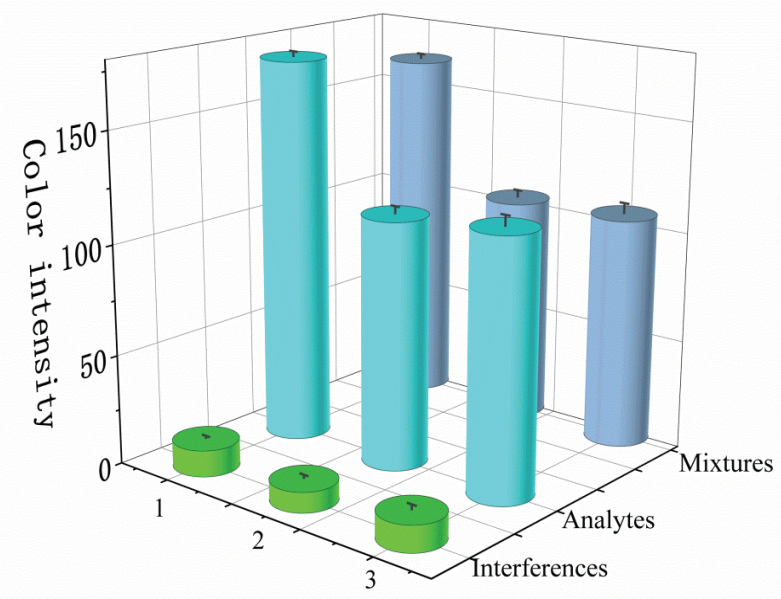

Figure 5. Interference study of the microfluidic paper-based analytical device. 1 BSA detection zone, 2 Fe(III) detection zone, $3 \mathrm{Ni}(\mathrm{II})$ detection zone.

\section{Interference Study}

$\mathrm{Na}(\mathrm{I}), \mathrm{Co}(\mathrm{II}), \mathrm{Mg}(\mathrm{II}), \mathrm{Ca}(\mathrm{II}), \mathrm{Cd}(\mathrm{II}), \mathrm{Al}(\mathrm{III})$ were chosen as typical interference ions. We investigated the color intensity of mixtures containing Fe(III), $\mathrm{Ni}(\mathrm{II}), \mathrm{BSA}$ and the six interference ions. The concentration of each interfering ion was $2 \mathrm{mM}$, and the concentrations of $\mathrm{Fe}(\mathrm{III}), \mathrm{Ni}(\mathrm{II})$ and BSA were $1 \mathrm{mM}$, $5 \mathrm{mM}, 0.03 \mathrm{mM}$, respectively. We also studied the color intensity of analytes of $\mathrm{Fe}(\mathrm{III}), \mathrm{Ni}(\mathrm{II}), \mathrm{BSA}$. Then the comparative results were shown in Figure 5. As expected, the color intensity of each analyte was similar to that of mixtures including analyte and interference ions, while the color intensity of the interferences was very low. This suggested that the interference ions had little effect on the colorimetric detection. Thus, the fabricated $\mu$ PADs possessed high selectivity and could be applied for the simultaneous detection of Fe(III), Ni(II), and BSA. Such high selectivity was the result of the masking effect of masking reagents, the selectivity of chromogenic reagents, and the specific reaction conditions optimized for the detection of each metal ion and BSA.

\section{Repeatability and Stability of the $\mu$ PAD}

We studied the repeatability and reproducibility on the developed $\mu \mathrm{PAD}$. The repeatability of the assay was evaluated by averaging 3 replicate analyses of $0.3 \mathrm{mM} \mathrm{Fe}(\mathrm{III}), 1 \mathrm{mM} \mathrm{Ni}(\mathrm{II})$ and $0.05 \mathrm{mM}$ BSA and calculating the relative standard deviation (\%RSD). The \%RSD was 1.6 for $\mathrm{Fe}(\mathrm{III}), 3$ for $\mathrm{Ni}(\mathrm{II})$ and 1.4 for BSA. The reproducibility of the devices was analyzed by using 3 different $\mu$ PADs for their detections of $0.1 \mathrm{mM} \mathrm{Fe}(\mathrm{III}), 5 \mathrm{mM} \mathrm{Ni}(\mathrm{II})$ and $0.03 \mathrm{mM}$ BSA,
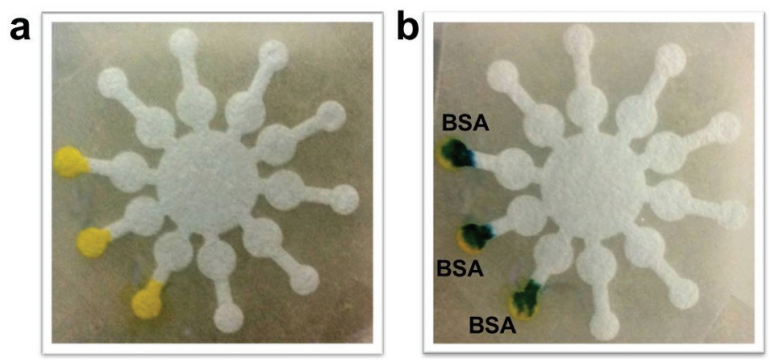

Figure 6. Simultaneous detection of $\mathrm{Fe}(\mathrm{III}), \mathrm{Ni}(\mathrm{II})$ and BSA in an actual river sample (a) $\mu \mathrm{PAD}$ with reaction mixture solutions and colorimetric reagents added. (b) $\mu$ PAD showing detection of an actual river sample.

and the RSD values obtained were $1.27 \%, 3.4 \%$ and $2.4 \%$ for $\mathrm{Fe}(\mathrm{III}), \mathrm{Ni}(\mathrm{II})$ and $\mathrm{BSA}$, respectively. All the results showed that the proposed $\mu \mathrm{PADs}$ had high accuracy.

The storage stability of the $\mu \mathrm{PAD}$ was tested by measuring the change of color intensity in a period of time. The color intensities of samples were 80,75 and $83 \%$ of initial values of $\mathrm{Fe}(\mathrm{III}), \mathrm{Ni}(\mathrm{II})$ and BSA, respectively, after a storage period of 3 months at room temperature and dark conditions.

\section{Application to Actual River Samples}

In order to evaluate the performance of $\mu \mathrm{PAD}$ in practical applications, river samples were analyzed by our device. Firstly, reaction mixture solutions were introduced into reaction zones 1-9. Secondly, colorimetric reagents were dropped into detection zones 1-9 respectively. Injection details were the same as described in method part. Thirdly, $30 \mu$ river water sample was added to the center zone of the prepared $\mu$ PADs. Note, the detection zone 10 was used as a control zone. It took only 15 mins from the addition of various reaction solutions to the end of the detection. As shown in Figure 6, the color of detection zones 7-9 changed from yellow to dark green, indicating the presence of BSA residues in the sample. According to the established color palettes and calibration curves respectively, the concentration of BSA in the sample was about $0.1 \mathrm{mM}$. There was no color change in detection zones 1-6, indicating no heavy metal ions $\mathrm{Fe}(\mathrm{III})$ or $\mathrm{Ni}(\mathrm{II})$ within the detection range in the sample. Accordingly, it can be quantitatively concluded that the river water was safe in the level of $\mathrm{Fe}(\mathrm{III})$ or $\mathrm{Ni}(\mathrm{II})$.

In views of actual applications compared with chromatography ${ }^{16-17}$, our colorimetric analysis ${ }^{35-40}$ based on $\mu$ PAD shows many advantages. Firstly, the amount of reagents used for one sample detection is within 
$100 \mu \mathrm{l}$, while the chromatography method needs about $100 \mathrm{ml}$. Secondly, the average analysis time is within 15 mins, while the compared method needs 30 mins. Thirdly, the operation part of our method is to inject drops with a liquid gun, while the chromatography method needs special skills in the operation of instrument. Fourthly, the size of a $\mu \mathrm{PAD}$ is about $2.5 \times$ $2.5 \mathrm{~cm}$ and the weight is within $100 \mathrm{~g}$, which is easier to carry to the real environment comparing to carry chromatographic equipment. Finally, the cost of fabricating a device and analyzing a sample is about $\$ 10$ for our method, while the cost is high by a chromatography method.

\section{Conclusions}

In this work, simultaneous determination of protein and metal ions was performed using a cheaper, simpler, faster, more portable, and easier to use method, compared to the conventional method. To the best of our knowledge, this is the first simultaneous detection of $\mathrm{Fe}(\mathrm{III}), \mathrm{Ni}(\mathrm{II})$ and BSA based on a $\mu$ PAD. High-contrast color palettes were obtained by optimizing the volume of $\mu \mathrm{PAD}$ and parameters of reaction solution. The reproducible log-linear calibration curves were further established correlating color intensity with concentrations of analytes. The limits of detection are $0.1 \mathrm{mM}$ for $\mathrm{Fe}(\mathrm{III}), 0.5 \mathrm{mM}$ for $\mathrm{Ni}(\mathrm{II})$ and $1 \mu \mathrm{M}$ for BSA. The linear ranges are 0.1 to $5 \mathrm{mM}$ for $\mathrm{Fe}(\mathrm{III}), 1-50 \mathrm{mM}$ for $\mathrm{Ni}(\mathrm{II})$ and 1-100 $\mu \mathrm{M}$ for BSA. The accuracy and stability of the method were evaluated in a satisfied result. We verified that the $\mu \mathrm{PAD}$ can effectively detect the content of $\mathrm{Fe}(\mathrm{III}), \mathrm{Ni}(\mathrm{II})$ and BSA in the natural water sample. Therefore, the proposed colorimetric $\mu$ PADs open the door for simultaneous detection of cross type samples in numerous diagnostic fields.

\section{Materials and Methods}

\section{Chemicals and Materials}

Iron (III) standard solution (17.9 mM), Nickel (II) sulfate hexahydrate and $\mathrm{Na}(\mathrm{I}), \mathrm{Co}(\mathrm{II}), \mathrm{Mg}(\mathrm{II}), \mathrm{Ca}(\mathrm{II})$, $\mathrm{Cd}(\mathrm{II}), \mathrm{Al}(\mathrm{III})$ standard solution were purchased from Sigma-Aldrich Corp. Bovine serum albumin (BSA), phenanthroline, dimethylglyoxime (DMG), tetrabromophenol blue (TBPB), hydroxylammonium chloride, ammomium acetate, sodium fluoride $(\mathrm{NaF})$, sodium citrate, ammonium hydroxide and hydrochloric acid were purchased from Aladdin Industrial Corp. All reagents used in the experiment were analytical grade.
$2 \mathrm{mM}$ TBPB and $2 \mathrm{mg} / \mathrm{ml}$ DMG solution were prepared individually with ethanol. $0.156 \mathrm{~g} / \mathrm{ml}$ hydroxylammonium chloride solution, $0.48 \mathrm{mg} / \mathrm{ml}$ ammomium acetate solution, $0.5 \mathrm{M} \mathrm{NaF}$ and $10 \mathrm{mM}$ sodium citrate buffer solution were diluted with ultrapure water. Reaction mixture solution 1 was prepared by mixing ammonium acetate and hydroxylammonium chloride solution at 1:1 for Fe(III) detection. Reaction mixture solution 2 was made by mixing sodium fluoride, acetic acid and ammonium hydroxide solution at 2:1:4 for $\mathrm{Ni}(\mathrm{II})$ detection. Reaction mixture solution 3 was obtained by mixing sodium citrate and hydrochloric acid at 1:1 for BSA detection. The standard solutions (0.1-17.9 mM Fe(III), 0.5-200 mM Ni(II) and 0.001-0.2 mM BSA) were prepared by diluting purchased mother liquor with ultrapure water. The river water samples were collected from the Wo River in Henan province of China.

Whatman grade 1 filter paper was purchased from Whatman International Ltd. SU-8 GM-1075 was purchased from Gersteltec Corp. Ultrapure water was obtained from a minipore water purification system. The commercial UV exposure machine (Carl Suss MA6, Germany) and plasma degumming machine (PVA Tepla, Germany) were used to fabricate the paper-based device.

\section{Design and Fabrication of $\mu$ PADs}

Patterns of $\mu$ PADs were drawn by L-edit software. As shown in Figure 1, four $\mu$ PADs were designed and arrayed in one mask and each $\mu$ PAD consisted of a centre zone (10 $\mathrm{mm}$ diameter), 10 reaction zones (3 $\mathrm{mm}$ diameter for each zone) and 10 detection zones ( $2.5 \mathrm{~mm}$ diameter for each zone) connected through narrow channels. The channel length between the reaction and center zone was $1 \mathrm{~cm}$, and the channel length between the reaction and detection zone was 3 $\mathrm{cm}$. 10 reaction zones and 10 detection zones were designed for simultaneous assay of $\mathrm{Fe}(\mathrm{III}), \mathrm{Ni}(\mathrm{II})$ and BSA in different concentrations.

The $\mu \mathrm{PAD}$ was fabricated by UV-exposure method referred by Whites ${ }^{27-28}$. The main processes of fabrication are shown in Figure 1. Firstly we cut a whatman1 paper into the shape of 4- inch silicon wafer and poured about $20 \mathrm{ml}$ of SU-8 GM-1075 onto the paper fixed on a clean silicon wafer. Secondly the paper was coated with photoresist at $1700 \mathrm{rpm}$ for $100 \mathrm{~s}$ and prebaked at $40^{\circ} \mathrm{C}$ for $30 \mathrm{~min}$ and at $120^{\circ} \mathrm{C}$ for $2 \mathrm{~min}$. Afterwards, the photoresist was exposed to $365 \mathrm{~nm}$ UV light by UV exposure machine for $6 \mathrm{~s}$ and baked at $95^{\circ} \mathrm{C}$ for $30 \mathrm{~min}$. Next, the unpolymerized photoresist was removed by soaking the paper in PGMEA for $3 \mathrm{~min}$ and by rinsing the pattern with 
isopropyl alcohol for $1 \mathrm{~min}$. Then the surface was exposed to oxygen plasma for $60 \mathrm{~s}$ with $150 \mathrm{~W}$ plasma power by plasma degumming machine. Finally, the back of the paper surface was covered with packing tapes to prevent solution leakage.

\section{Detection Procedures for $\mu$ PADs}

We used three $\mu$ PADs for exploring the detection limit and detection range of $\mathrm{Fe}(\mathrm{III}), \mathrm{Ni}(\mathrm{II})$ and BSA. For the first $\mu \mathrm{PAD}, 3$ pieces of $1.5 \mu \mathrm{l}$ reaction mixture solution 1 for $\mathrm{Fe}(\mathrm{III})$ were added into reaction zones $1-3$, respectively. 3 pieces of $1.5 \mu$ reaction mixture solution 2 for $\mathrm{Ni}(\mathrm{II})$ were added into reaction zones $4-6$, respectively. 4 pieces of $1.5 \mu l$ reaction mixture solution 3 for BSA were added into reaction zones 7-10, respectively. Next, 3 pieces of $0.5 \mu \mathrm{l}$ phenanthroline solutions were dropped into detection zones $1-3$, respectively. 3 pieces of $0.5 \mu \mathrm{DMG}$ solutions were individually dropped into detection zones 4-6. 4 pieces of $0.5 \mu$ tetrabromophenyl blue solutions were dropped into detection zones 7-10, respectively. Finally, standard solutions $(0.1,0.7,5 \mathrm{mM}$ $\mathrm{Fe}(\mathrm{III}), 0.5,5,50 \mathrm{mM} \mathrm{Ni}(\mathrm{II})$ and $0.001,0.03,0.1 \mathrm{mM}$ BSA) were introduced into detection zones 1-9, respectively. Note, the detection zone 10 was used as a control zone.

For the second and third $\mu$ PADs, reaction mixture solutions and colorimetric reagents were first added in the same way as the first device. Next, for the second device, standard solutions including $0.3,1,10$ $\mathrm{mM}$ Fe(III), 1, 10, $100 \mathrm{mM} \mathrm{Ni(II),} \mathrm{0.005,} \mathrm{0.05,} 0.15$ $\mathrm{mM}$ BSA were individually injected into detection zones 1-9. For the third device, standard solutions including $0.5,3,17.9 \mathrm{mM} \mathrm{Fe}(\mathrm{III}), 2,20,200 \mathrm{mM} \mathrm{Ni}(\mathrm{II})$, $0.01,0.07,0.2 \mathrm{mM}$ BSA were added into detection zones 1-9, respectively. Note, each detection repeated above 5 times.

\section{Establishment of Calibration Curves}

After the color products were formed, $\mu$ PADs dried for $1 \mathrm{~min}$ at room temperature and were imaged using an iPad mini camera. ImageJ software was used to convert the image to 8-bit grayscale and evaluate the color intensity. Calibration curves were established by drawing the functional relationship between the color intensity and the concentration, and used as references for actual samples detecting.

Acknowledgements This work is funded by the National Natural Science Foundation of China (NSFC) (11734003 and 51661135026), the National Key Re- search and Development Program of China (2016YF A0300600 \& 2016YFA0300904).

Conflict of Interests The authors declare no competing financial interests.

\section{References}

1. Nam, J.M., Thaxton, C.S. \& Mirkin, C.A. Nanoparticle-based bio-bar codes for the ultrasensitive detection of proteins. Science 301,1884-1886 (2003).

2. Liu, S., Zhang, X., Luo, W., Wang, Z., Guo, X., Steigerwald, M.L. \& Fang, X. Single-molecule detection of proteins using aptamer-functionalized molecular electronic devices. Angew. Chem. Int. Ed. 50, 2496-2502 (2011).

3. Frank, R. \& Hargreaves, R. Clinical biomarkers in drug discovery and development. Nat. Rev. Drug Discovery 2, 566-580 (2003).

4. Johnson, S. Iron catalyzed oxidative damage, in spite of normal ferritin and transferrin saturation levels and its possible role in Werner's syndrome, Parkinson's disease, cancer, gout, rheumatoid arthritis, etc. Med. Hypotheses 55, 242-244 (2000).

5. Shi, Z. Nickel carbonyl: toxicity and human health. Sci. Total Environ. 148, 293-298 (1994).

6. Arora, M., Kiran, B., Rani, S., Rani, A., Kaur, B. \& Mittal, N. Heavy metal accumulation in vegetables irrigated with water from different sources. Food Chem. 111, 811-815 (2008).

7. Kingsmore, S.F. Multiplexed protein measurement: technologies and applications of protein and antibody arrays. Nat. Rev. Drug Discovery 5, 310-320 (2006).

8. Ma, H., An, R., Chen, L., Fu, Y., Ma, C., Dong, X. \& Zhang, X. A study of the photodeposition over $\mathrm{Ti} / \mathrm{TiO} 2$ electrode for electrochemical detection of heavy metal ions. Electrochem. Commun. 57, 18-21 (2015).

9. Posta, J., Berndt, H., Luo, S.-K. \& Schaldach, G. High-performance flow flame atomic absorption spectrometry for automated on line separation and determination of $\mathrm{Cr}(\mathrm{III}) / \mathrm{Cr}(\mathrm{VI})$ and preconcentration of Cr(VI). Anal. Chem. 65, 2590-2595 (1993).

10. Paleologos, E.K., Lafis, S.I., Tzouwara-Karayanni, S.M. \& Karayannis, M.I. Speciation analysis of CrIII-CrVI using flow injection analysis with fluorimetric detection. Analyst 123, 1005-1009 (1998).

11. Ullah, N., Mansha, M., Khan, I. \& Qurashi, I. Nanomaterial-based optical chemical sensors for the detection of heavy metals in water: recent advances and challenges. TrAC, Trends Anal. Chem. 100, 
155-166 (2018).

12. Scott, A.W., Garimella, V., Calabrese, C.M. \& Mirkin, C.A. Universal biotin-PEG-linked gold Nanoparticle probes for the simultaneous detection of nucleic acids and proteins. Bioconjugate Chem. 28, 203-211 (2017).

13. Kuhn, H.R. \& Günther, D. Elemental fractionation studies in laser ablation inductively coupled plasma mass spectrometry on laser-induced brass aerosols. Anal. Chem. 75, 747-753 (2003).

14. Wu, J., Yu, J., Li, J., Wang, J. \& Ying, Y. Detection of metal ions by atomic emission spectroscopy from liquid-electrode discharge plasma. Spectrochim. Acta, Part B 62, 1269-1272 (2007).

15. Amin, N., Siddiqi, H.M., Lin, Y.K., Hussain, Z. \& Majeed, N. Bovine serum albumin protein-based liquid crystal biosensors for optical detection of toxic heavy metals in water. Sensors 20, 298 (2020).

16. Fredrikson, M., Carlsson, N.-G., Almgren, A. \& Sandberg, A.-S. Simultaneous and sensitive analysis of $\mathrm{Cu}, \mathrm{Ni}, \mathrm{Zn}, \mathrm{Co}, \mathrm{Mn}$, and $\mathrm{Fe}$ in food and biological samples by ion chromatography. J. Agric. Food Chem. 50, 59-65 (2002).

17. Gjoka, X., Schofield, M., Cvetkovic, A. \& Gantier, R. Combined protein A and size exclusion high performance liquid chromatography for the single-step measurement of $\mathrm{mAb}$, aggregates and host cell proteins. J. Chromatogr. B: Anal. Technol. Biomed. Life Sci. 972, 48-52 (2014).

18. Sriram, G., Bhat, M.P., Patil, P., Uthappa, U.T., Jung, H.-Y., Altalhi, T., Kumeria, T., Aminabhavi, T.M., Pai, R.K., Madhuprasad \& Kurkuri, M.D. Paper-based microfluidic analytical devices for colorimetric detection of toxic ions: a review. $\operatorname{Tr} A C$, Trends Anal. Chem. 93, 212-227 (2017).

19. Hossain, S.M.Z. \& Brennan, J.D. $\beta$-Galactosidasebased colorimetric paper sensor for determination of heavy metals. Anal.Chem. 83, $8772-8778$ (2011).

20. Teengam, P., Siangproh, W., Tuantranont, A., Vilaivan, T., Chailapakul, O. \& Henry, C.S. Multiplex paper-based colorimetric DNA sensor using pyrrolidinyl peptide nucleic acid-induced AgNPs aggregation for detecting MERS-CoV, MTB, and HPV oligonucleotides. Anal. Chem. 89, 5248-5435 (2017).

21. Karita, S., \& Kaneta, T. Chelate titrations of $\mathrm{Ca}^{2+}$ and $\mathrm{Mg}^{2+}$ using microfluidic paper-based analytical devices. Anal. Chim. Acta 924, 60-67 (2016).

22. Mentele, M.M, Cunningham, J., Koehler, K., Volckens, J. \& Henry, C.S. Microfluidic paper-based analytical device for particulate metals. Anal. Chem. 84, 4474-4480 (2012).

23. Jayawardane, B.M., Wongwilai, W., Grudpan, K.,
Kolev, S.D., Heaven, M.W., Nash, D.M. \& McKelvie, I.D. Evaluation and application of a paper-based device for the determination of reactive phosphate in soil solution. J. Environ. Qual. 43, 1081-1085 (2014).

24. Li, F., Hu, Y., Li, Z., Liu, J., Guo, L. \& He, J. Three-dimensional microfluidic paper-based device for multiplexed colorimetric detection of six metal ions combined with use of a smartphone. Anal. Bioanal. Chem. 411, 6497-6508 (2019).

25. Aksorn, J. \& Teepoo, S. Development of the simultaneous colorimetric enzymatic detection of sucrose, fructose and glucose using a microfluidic paperbased analytical device. Talanta 207, 120302 (2020).

26. Zhang, Y., Zuo, P. \& Ye, B.C. A low-cost and simple paper-based microfluidic device for simultaneous multiplex determination of different types of chemical contaminants in food. Biosens. Bioelectron. 68, 14-19 (2015).

27. Martinez, A.W., Phillips, S.T., Butte, M.J. \& Whitesides, G.M. Patterned paper as a platform for inexpensive, low-volume, portable bioassays. Angew. Chem. Int. Ed. 46, 1318-1320 (2007).

28. Martinez, A.W., Phillips, S.T., Wiley, B.J., Gupta, M. \& Whitesides, G.M. FLASH:A rapid method for prototyping paper-based microfluidic devices. $L a b$ Chip 8, 2146-2150 (2008).

29. Sun, X., Li, B., Qi, A., Tian, C., Han, J., Shi, Y., Lin, B. \& Chen, L. Improved assessment of accuracy and performance using a rotational paper based device for multiplexed detection of heavy metals. Talanta 178, 426-431 (2018).

30. Ding, J., Li, B., Chen, L. \& Qin, W. A three- dimensional origami paper-based device for potentiometric biosensing. Angew. Chem. Int. Ed. 55, 13033-13037 (2016).

31. Yang, M., Zhang, W., Zheng, W., Cao, F. \& Jiang, $\mathrm{X}$. Inkjet-printed barcodes for a rapid and multiplexed paper-based assay compatible with mobile devices. Lab Chip 17, 3874-3882 (2017).

32. Li, X., Tian, J., Garnier, G. \& Shen, W. Fabrication of paper-based microfluidic sensors by printing. Colloids Surf., B 76, 564-570 (2010).

33. Asano, H. \& Shiraishi, Y. Development of paperbased microfluidic analytical device for iron assay using photomask printed with 3D printer for fabrication of hydrophilic and hydrophobic zones on paper by photolithography. Anal. Chim. Acta 883, 55-60 (2015).

34. Rattanarat, P. et al. Multilayer paper-based device for colorimetric and electrochemical quantification of metals. Anal. Chem. 86, 3555-3562 (2014). 
35. Patil, P., Madhuprasad, Bhat, M.P., Gatti, M.G., Kabiri, S., Altalhi, T., Jung, H.-Y., Losic, D. \& Kurkuri, M. Chemodosimeter functionalized diatomaceous earth particles for visual detection and removal of trace mercury ions from water. Chem. Eng. J. 327, 725-733 (2017).

36. Wei, S.Q., Chen, G., Jia, X., Mao, X., Chen, T., Mao, D., Zhang, W. \& Xiong, W. Exponential amplification reaction and triplex DNA mediated aggregation of gold nanoparticles for sensitive colorimetric detection of microRNA. Anal. Chim. Acta 1095,179-184 (2020).

37. Zhang, X., Wang, C.Y. \& Gao, Y.F. Cerium(III)doped $\mathrm{MoS}_{2}$ nanosheets with expanded interlayer spacing and peroxidase-mimicking properties for colorimetric determination of hydrogen peroxide.
Microchim. Acta 187, 111 (2020).

38. Bhat, M.P., Madhuprasad, Patil, P., Nataraj, S.K., Altalhi, T., Jung, H.-Y., Losic, D. \& Kurkuri, M.D. Turmeric, naturally available colorimetric receptor for quantitative detection of fluoride and iron. Chem. Eng. J. 303, 14-21 (2016).

39. Bhat, M.P., Kigga, M., Govindappa, H., Patil, P., Jung, H.-Y., Yu, J. \& Kurkuri, M. A reversible fluoride chemosensor for the development of multi-input molecular logic gates. New J. Chem. 43, 12734-12743 (2019).

40. Patil, P., Ajeya, K.V., Bhat, M.P. \& Sriram, G. Real-time probe for the efficient sensing of inorganic fluoride and copper ions in aqueous media. ChemistrySelect 3, 11593-11600 (2018).

Copyright for the published papers belongs to the Korean BioChip Society. pISSN 1976-0280. eISSN 2092-7843. 